\title{
Storage and Uptake of D-Serine into Astrocytic Synaptic-Like Vesicles Specify Gliotransmission
}

\author{
Magalie Martineau, ${ }^{1,2}$ Ting Shi, ${ }^{3}$ Julien Puyal, ${ }^{4}$ Ann M. Knolhoff, ${ }^{3}$ Jérôme Dulong, ${ }^{1,2}$ Bruno Gasnier, ${ }^{5}$ Jürgen Klingauf, \\ Jonathan V. Sweedler, ${ }^{3}$ Reinhard Jahn, ${ }^{7}$ and Jean-Pierre Mothet ${ }^{1,2,8}$ \\ ${ }^{1}$ Neurocentre Magendie, National Institute of Health and Medical Research, Unit 862 and ${ }^{2}$ University of Bordeaux, F-33077 Bordeaux, France, ${ }^{3}$ Department \\ of Chemistry and Neuroscience Program, University of Illinois, Urbana, Illinois 61801, ${ }^{4}$ Department of Fundamental Neurosciences, University of \\ Lausanne, CH-1005 Lausanne, Switzerland, ${ }^{5}$ University Paris Descartes, Sorbonne Paris Cité, National Center for Scientific Research, Joint Research Unit \\ 8192, F-75006 Paris, France, ${ }^{6}$ Institute of Medical Physics and Biophysics, University of Muenster, D-48149 Muenster, Germany, ${ }^{7}$ Department of \\ Neurobiology, Max Planck Institute for Biophysical Chemistry, D-37077 Goettingen, Germany, and ${ }^{8}$ Aix-Marseille University, National Center for Scientific \\ Research, CRN2M, Joint Research Unit 7286, F-13344 Marseille, France
}

Glial cells are increasingly recognized as active players that profoundly influence neuronal synaptic transmission by specialized signaling pathways. In particular, astrocytes have been shown recently to release small molecules, such as the amino acids L-glutamate and D-serine as "gliotransmitters," which directly control the efficacy of adjacent synapses. However, it is still controversial whether gliotransmitters are released from a cytosolic pool or by $\mathrm{Ca}^{2+}$-dependent exocytosis from secretory vesicles, i.e., by a mechanism similar to the release of synaptic vesicles in synapses. Here we report that rat cortical astrocytes contain storage vesicles that display morphological and biochemical features similar to neuronal synaptic vesicles. These vesicles share some, but not all, membrane proteins with synaptic vesicles, including the SNARE (soluble $\mathrm{N}$-ethylmaleimide-sensitive factor attachment protein receptor) synaptobrevin 2, and contain both L-glutamate and D-serine. Furthermore, they show uptake of L-glutamate and D-serine that is driven by a proton electrochemical gradient. D-Serine uptake is associated with vesicle acidification and is dependent on chloride. Whereas L-serine is not transported, serine racemase, the synthesizing enzyme for D-serine, is anchored to the membrane of the vesicles, allowing local generation of D-serine. Finally, we reveal a previously unexpected mutual vesicular synergy between D-serine and L-glutamate filling in glia vesicles. We conclude that astrocytes contain vesicles capable of storing and releasing D-serine, L-glutamate, and most likely other neuromodulators in an activity-dependent manner.

\section{Introduction}

Glial cells and particularly astrocytes control synaptic strength and hence participate in normal and pathological brain function

\section{Received July 22, 2012; revised Dec. 11, 2012; accepted Dec. 21, 2012}

Author contributions: M.M., B.G., J.V.S., R.J., and J.-P.M. designed research; M.M., T.S., J.P., A.M.K., J.D., and J.-P.M. performed research; J.K. and R.J. contributed unpublished reagents/analytic tools; M.M., T.S., J.P., A.M.K., J.V.S., and J.-P.M. analyzed data; M.M., R.J., and J.-P.M. wrote the paper.

This work was supported by grants from the National Center for Scientific Research (J.P.M., B.G.), National Institute of Health and Medical Research (J.P.M.), Regional Council of Aquitaine (J.P.M.), National Research Agency (J.P.M.), and Swiss National Science Foundation (J.P.), National Science Foundation Grants CHE-1111705 and CHE0526692 (J.V.S.), and National Institute of Health Grant P30DA018310 (J.V.S.). M.M. is a recipient of a PhD fellowship from the National Ministry of Education, Research, and Technology, from the Foundation of Medical Research, and was granted by the European Molecular Biology Organisation for a short-term fellowship. The monoclonal antibodies against $\mathrm{Na}^{+} / \mathrm{K}^{+}$-ATPase $(\alpha 6 \mathrm{~F})$ developed by D. M. Fambrough and against SV2 developed by K. M. Buckley were obtained from the Developmental Studies Hybridoma Bank developed under the auspices of the National Institute of Child Health and Human Development and maintained by the University of lowa, Department of Biological Sciences (lowa City, IA). We are grateful to Dionysia T. Theodosis for her technical help in electron microscopy analysis of purified vesicles, to Rosina Giordano for launching preliminary radioactivity uptake experiments, to Peter Nemes for his assistance with CE-MS, and to Stéphane H. R. Oliet for his continuous support. We thank Shigeo Takamori and Paola Bezzi for their valuable comments and suggestions. We are grateful to Thierry Galli, Nicolas Morel, and Herman Wolosker for generously providing antibodies and to Silvia Sacchi and Loredano Pollegioni for the generous gift of RgDAA0 and Bsglycine oxidase. We thank the Photonic Imaging team of the Bordeaux Imaging Center for its technical assistance and expertise and the Center of Electron Microscopy at the University of Lausanne for the use of their electron microscopes. We thank one of the reviewers for a valuable experimental suggestion.

Correspondence should be addressed to either of the following at their present addresses: Dr. Jean-Pierre Mothet, Aix-Marseille University, National Center for Scientific Research, CRN2M, Joint Research Unit 7286, F-13344 Marseille, France, E-mail: jean-pierre.mothet@univ-amu.fr; or Dr. Magalie Martineau, Institute of Medical Physics and Biophysics, University of Muenster, D-48149 Muenster, Germany, E-mail: magmart@uni-muenster.de.

DOI:10.1523/JNEUROSCI.3497-12.2013

Copyright $\odot 2013$ the authors $\quad 0270-6474 / 13 / 333413-11 \$ 15.00 / 0$
(Halassa and Haydon, 2010) through the regulated release of neuromodulators called gliotransmitters (Volterra and Meldolesi, 2005). The mechanisms for gliotransmitter release remain ill-defined. Two main routes have been proposed: (1) nonexocytotic release from cytosolic pools by membrane proteins, and (2) $\mathrm{Ca}^{2+}$-regulated exocytosis, which requires the storage of gliotransmitters in secretory organelles (Volterra and Meldolesi, 2005; Halassa and Haydon, 2010; Hamilton and Attwell, 2010).

Among gliotransmitters, D-serine is recognized as an important signaling molecule that gates the activity of the synaptic NMDA receptors in many brain areas (Mothet et al., 2000; Panatier et al., 2006; Henneberger et al., 2010; Fossat et al., 2012). Besides its physiological functions, D-serine promotes excitotoxicity when released in excess (Martineau et al., 2006). Hence, deletion of the biosynthetic enzyme serine racemase (SR) confers neuronal protection against ischemic and related cerebral injuries (Inoue et al., 2008; Mustafa et al., 2010).

Several lines of physiological evidence have suggested that glia may exocytose D-serine. Indeed, release is triggered by calcium rises and is inhibited by both tetanus neurotoxin and blockers of V-ATPase (Mothet et al., 2005; Martineau et al., 2008). Also, D-serine immunoreactivity colocalizes with markers of the regulated secretory pathway such as the SNARE [soluble $N$-ethylmaleimide-sensitive factor attachment protein (SNAP) receptor] synaptobrevin 2 (Sb2) (Martineau et al., 2008). Furthermore, tetanus neurotoxin injection or cytosolic calcium 

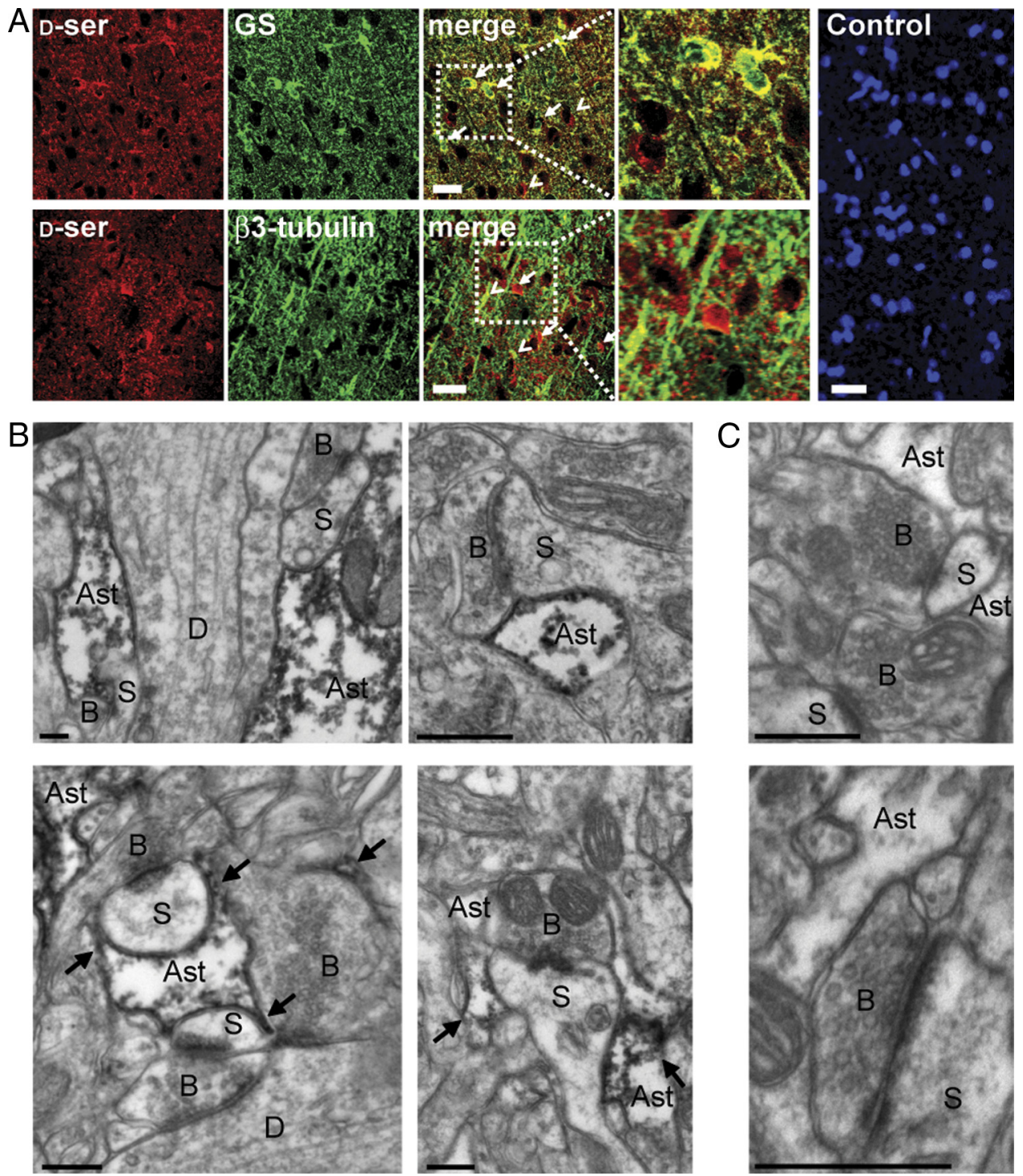

Figure 1. D-Serine distribution in the rat cerebral cortex. $A$, Confocal microscopy analysis of immunostainings of $\mathrm{D}$-serine versus astroglial [glutamine synthase (GS)] or neuronal ( $\beta 3$-tubulin) markers in the rat cerebral cortex. Arrowheads, D-Serine-containing neurons; arrows, D-serine-positive astrocytes; Control, staining with a nuclear marker, DAPI (blue), and an anti-D-serine antibody previously preabsorbed with $500 \mu \mathrm{m}$ liquid-phase D-serine glutaraldehyde conjugate. Scale bars, $30 \mu \mathrm{m}$. B. Representative electron micrographs of D-serine preembedding immunohistochemistry using the peroxidase method showing that D-serine immunoreactivity is mainly distributed in astrocytic processes (arrows) at the level of asymmetric synapses in the rat cerebral cortex. $C$, Representative low-magnification (top) and high-magnification (bottom) electron micrographs showing that no peroxidase staining is detected with a preabsorbed anti-D-serine antibody. Ast, Astrocyte; D, dendrite; S, dendritic spine; B, axonal bouton. Scale bars, $500 \mathrm{~nm}$.

clamping suppressed long-term potentiation in the Schaffer collateral-CA1 pyramidal cell synapses (Henneberger et al., 2010); these inhibitory effects were fully reversed by adding D-serine. Interestingly, L-glutamate, another important gliotransmitter, undergoes $\mathrm{Ca}^{2+}$ - and SNARE-dependent release to modulate synaptic functions (Araque et al., 2000; Bezzi et al., 2004; Montana et al., 2004; Jourdain et al., 2007).

Nevertheless, the evidence for exocytotic release of D-serine and L-glutamate is mostly indirect, and the exocytotic release hypothesis is confounded by the observation that glial cells can also release these gliotransmitters through non-exocytotic mechanisms (for review, see Volterra and Meldolesi, 2005; Hamilton and Attwell, 2010). Thus, it cannot be excluded that tetanus neurotoxin or calcium clamping inhibits the regulated exocytotic insertion of transporters or ion channels into the plasma membrane, which are needed for (stimulated) release of gliotransmitters.
Another issue with the general acceptance for $\mathrm{Ca}^{2+}$-regulated exocytosis of gliotransmitters is that the nature of the putative storage organelles is unknown. Furthermore, scant information exists about the mechanisms by which gliotransmitters are sequestered and stored. Therefore, obtaining such evidence is of fundamental importance for proving the concept of D-serine and L-glutamate exocytosis. Here we have performed a detailed analysis of the contents and uptake features of Sb2-bearing secretory organelles isolated from astrocytes using multiple experimental approaches. We show that Sb2-positive glial secretory vesicles have morphological and biochemical features similar to synaptic vesicles (SVs) and store both L-glutamate and D-serine. Uptake of these gliotransmitters is energized by a proton electrochemical gradient generated by a V-ATPase and critically depends on chloride ions. Finally, we show that synthesis and vesicular uptake of D-serine are coupled and that a mutual synergy exists between D-serine and L-glutamate uptakes in astroglial vesicles. 

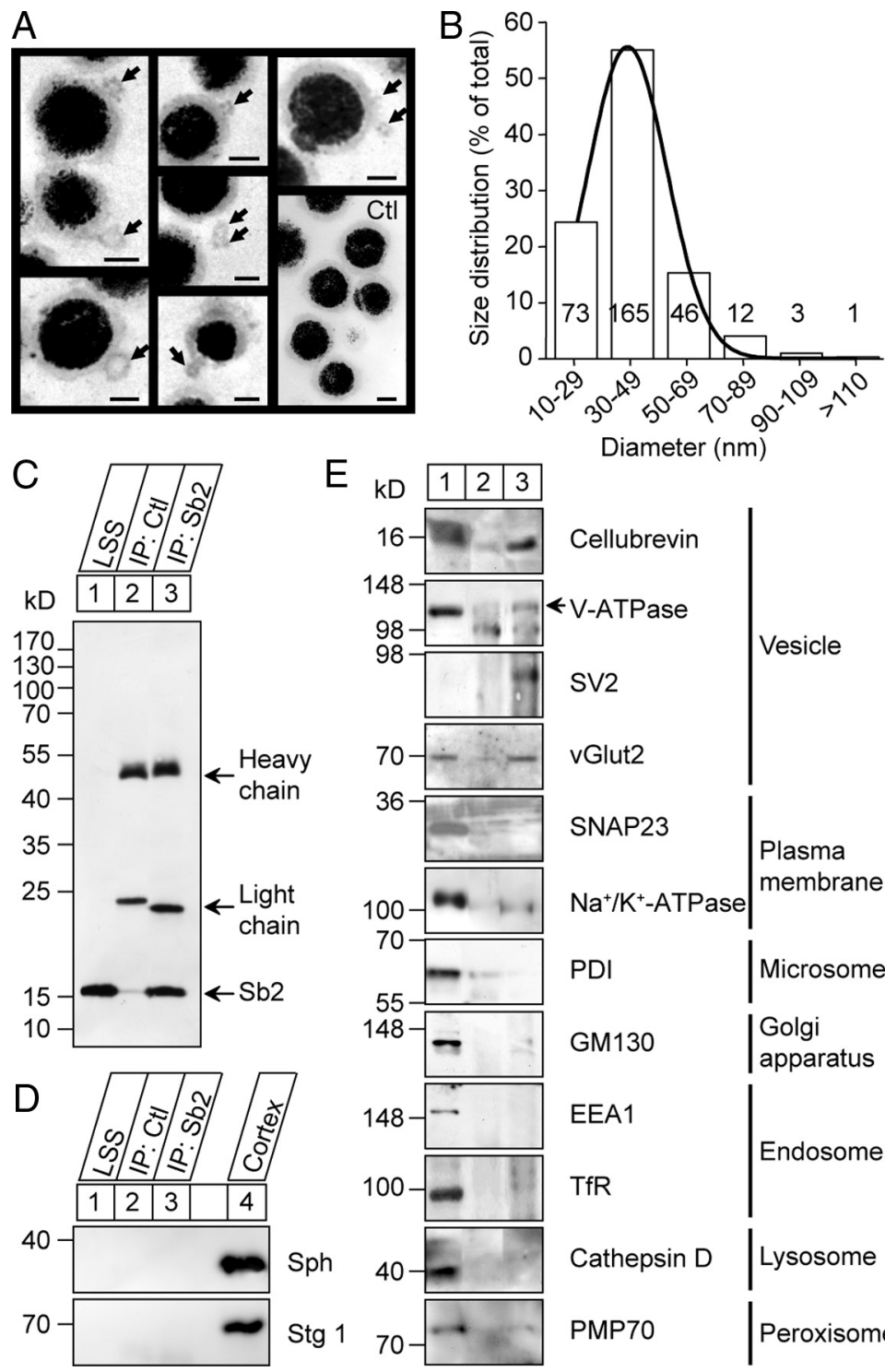

E

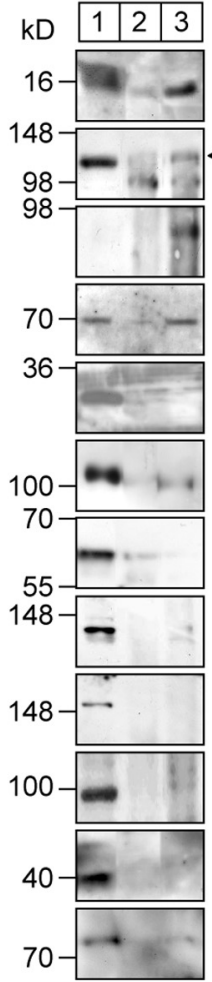

Cellubrevin

V-ATPase

SV2

vGlut2

SNAP23 $\mathrm{Na}^{+} / \mathrm{K}^{+}-\mathrm{ATPase}$

PDI

GM130

EEA1

TfR

Cathepsin D

PMP70
Vesicle

Plasma membrane

Microsome

Golgi apparatus

Endosome

Lysosome

Peroxisome
Figure 2. Characterization of GVs, immunoisolated from cultured astrocytes using beads coated with anti-Sb2 monoclonal antibodies. $A$, Electron micrographs of the bead fraction, showing vesicles bound to the surface of the beads. Ctl, Immunobeads coated with mouse lgG that were processed in parallel; no bound vesicles are detectable. Arrows, Bead-bound vesicles. Scale bars, $100 \mathrm{~nm}$. B, Size distribution of the immunoisolated vesicles. A total of 300 vesicles was measured, with the numbers falling into the respective categories indicated in the histogram. The black curve shows a Gaussian fit of the size distribution. C, Astroglial LSS and bead-bound material (IP) were immunoblotted for Sb2. Equal proportion of samples was loaded showing that a major fraction of Sb2-positive organelles was recovered in the bead fraction. Light and heavy chains correspond to light and heavy chains of mouse control (lane 2) and monoclonal anti-Sb2 antibodies (lane 3). D, E, Immunoblots of the fractions shown in C for various marker proteins specific for SVs $(\boldsymbol{D})$ and subcellular compartments $(\boldsymbol{E})$. Sph, Synaptophysin; Stg 1, synaptotagmin 1. agents), and glial fibrillary acidic protein (GFAP; Dako). Rabbit polyclonal antibodies against SR, SNAP23, and V-ATPase were kind gifts from Herman Wolosker (Technion-Israel Institute of Technology, Haifa, Israel), Thierry Galli (National Institute of Health and Medical Research, Paris, France), and Nicolas Morel (National Center of Scientific Research, Gif-sur-Yvette, France), respectively. Mouse monoclonal IgG1 was from Serotec. Secondary antibodies conjugated to horseradish peroxidase and Alexa Fluor 488 or 546 were obtained from P.A.R.I.S. and Invitrogen, respectively. Biotinylated donkey anti-rabbit antibody was from Jackson ImmunoResearch, and the goat anti-rabbit IgG coupled to $1.4 \mathrm{~nm}$ gold particles was from Nanoprobes.

Cell cultures. Cultured cortical astroglia cells were prepared from 0 - to 4 -d-old postnatal Wistar rats of either sex as described previously (Martineau et al., 2008). Cells were plated onto $150 \mathrm{~cm}^{2}$ flasks, kept at $37^{\circ} \mathrm{C}$ in a $5 \% \mathrm{CO}_{2}$ incubator for $14-20 \mathrm{~d}$. Astroglia culture purity $(>95 \%)$ was assessed by immunostaining against the astrocytic marker GFAP.

Organelle immunoisolation. All steps were performed at $4-6^{\circ} \mathrm{C}$ for Western blot and transport analysis or at $0^{\circ} \mathrm{C}$ for amino acid content analysis. For the immunoisolation of glial vesicles (GVs), cultured astroglial cells were washed, harvested by scraping, and resuspended in homogenization buffer $[4 \mathrm{~mm}$ HEPES-KOH, pH 7.4, $100 \mathrm{~mm} \mathrm{~K}_{2}$-tartrate, 2 $\mathrm{mM} \mathrm{MgCl}_{2}$, and protease inhibitor cocktail (Complete EDTA-free; Roche)]. Cells were homogenized using a cell cracker (clearance 10 $\mu \mathrm{m}$; European Molecular Biology Laboratory, Heidelberg, Germany), and the lysate was centrifuged for $10 \mathrm{~min}$ at $400 \times \mathrm{g}$. Low-speed supernatants (LSS) (containing $\sim 1 \mathrm{mg} / \mathrm{ml}$ protein) were incubated with monoclonal antibodies against $\mathrm{Sb} 2$ for $2 \mathrm{~h}$ under rotation and with magnetic beads coupled to protein $\mathrm{G}$ (Ademtech) for an additional $1 \mathrm{~h}$. The beads were further washed three times with homogenization buffer. Unbound membranes in the supernatant and LSS were pelleted by centrifugation at $175,000 \times g$ for $2 \mathrm{~h}$ in an 80Ti rotor. All membrane or bead pellets were resuspended in SDS-PAGE sample buffer before being processed for gel electrophoresis and immunoblotting with standard methods or in appropriate buffer for additional analysis. Isolations with murine IgG or at $21^{\circ} \mathrm{C}$ were used as a control.

\section{Materials and Methods}

Antibodies. Monoclonal antibody clones 69.1 against rat Sb2 was characterized previously (Edelmann et al., 1995). The antibodies against the following proteins were used: cathepsin D (Santa Cruz Biotechnology), cellubrevin (Covalab), D-serine (GemacBio), early endosome antigen 1 (EEA1) (clone 14) and Golgi matrix protein of $130 \mathrm{kDa}$ (GM130) (clone 35) (Transduction Laboratories), $\mathrm{Na}^{+} / \mathrm{K}^{+}$-ATPase and SV2 (Developmental Studies Hybridoma Bank), protein disulfide isomerase (PDI) (clone RL90; Abcam), $70 \mathrm{kDa}$ peroxisomal membrane protein (PMP70) (clone 70-18; Sigma), serine racemase (SR) (Santa Cruz Biotechnology; and clone 29, BD Biosciences), synaptophysin (clone 7.2; Synaptic Systems), synaptotagmin 1 (clone 604.1; Synaptic Systems), transferrin receptor (TfR) (clone H68.4; Invitrogen), vesicular glutamate transporter type 1 (vGlut1) and vGlut2 (Millipore), glutamine synthase (clone $\mathrm{SH}$ B1; Sigma), $\beta 3$-tubulin (clone TU-20; Millipore Bioscience Research Re-
Immunoisolation of SVs was performed following the same protocol, with the following modifications. The rat cerebral cortex of a male Wistar rat ( 2 months) was homogenized with a glass/Teflon homogenizer (10 strokes at $2500 \mathrm{rpm}$ ) in homogenization buffer immediately after decapitation. The homogenate was centrifuged for $25 \mathrm{~min}$ at $35,000 \times \mathrm{g}$. The resulting supernatant (containing $\sim 3 \mathrm{mg} / \mathrm{ml}$ protein) was incubated $1 \mathrm{~h}$ with anti-Sb2 and $1 \mathrm{~h}$ with magnetic beads.

Electron microscopy on isolated vesicles. Immunobeads with bound organelles were fixed in $3 \%$ glutaraldehyde in $0.1 \mathrm{~m}$ sodium cacodylate, $\mathrm{pH} 7.4$, for $1 \mathrm{~h}$ at room temperature. After a rinse in $0.1 \mathrm{M}$ sodium phosphate, $\mathrm{pH} 7.4$, the beads were embedded in $1 \%$ agarose in the same buffer. Agarose blocks were then postfixed for $1 \mathrm{~h}$ with $\mathrm{OsO}_{4}[1 \%$ in phosphate buffer $(\mathrm{PB})]$, dehydrated, and embedded in Epon. During dehydration, they were stained en bloc with uranyl acetate in $50 \%$ ethanol. Thin sections $(\sim 60 \mathrm{~nm})$ were counterstained with lead citrate and examined in a Philips 301 electron microscope. 
Electron microscopy on brain slices. Onemonth-old Sprague Dawley male rats were anesthetized (pentobarbital, $6 \mathrm{mg} / 100 \mathrm{mg}$ body weight) and perfused intracardially with a mix of glutaraldehyde ( 2.5 or $0.5 \%$ ) and paraformaldehyde ( 2 or $4 \%$ ) in $0.1 \mathrm{M} \mathrm{PB}$. For preembedding immunoperoxidase analyses, coronal brain vibratome sections $(60 \mu \mathrm{m})$ were pretreated with a cryoprotectant solution $(20 \%$ DMSO, 2\% glycerin in $\mathrm{PB}$ ) and then freeze thawed by freezing in isopentane and thawing in PB. Sections were pretreated with $1 \%$ $\mathrm{NaBH}_{4}$, preincubated in $15 \%$ donkey serum in PBS, incubated with anti-D-serine polyclonal antibody (1:2000), and finally incubated in biotinylated donkey anti-rabbit antibody (1:500) in PBS. The sections were treated with an avidin-biotinylated peroxidase mixture $(\mathrm{ABC}$ kit; Vector Laboratories), and peroxidase enzyme activity was then revealed using a $0.05 \%$ $3,3^{\prime}$-diaminobenzidine tetrahydrochloride solution added with $0.01 \% \mathrm{H}_{2} \mathrm{O}_{2}$. Sections for preembedding immunogold were incubated along with those used for immunoperoxidase up to the second antibody stage, then incubated in goat anti-rabbit IgG coupled to $1.4 \mathrm{~nm}$ gold particles (1:100), and postfixed in $1 \%$ glutaraldehyde for $10 \mathrm{~min}$, followed by silver enhancement of the gold particles with an HQ Silver kit (Nanoprobes). The specificity of the D-serine staining was assessed by incubating some sections with a "saturated" anti-D-serine polyclonal antibody (previously preabsorbed with $500 \mu \mathrm{m}$ liquid-phase D-serine glutaraldehyde conjugate) (Puyal et al., 2006) or without primary antibody. Under these conditions, no immunoreactivity was detected. Sections were then postfixed in $1 \% \mathrm{OsO}_{4}$, dehydrated in graded ethanol series, and flat-embedded in epoxy resin (Durcupan ACM; Fluka, Sigma-Aldrich) on glass slides. Ultrathin sections were done $(70-90 \mathrm{~nm})$, mounted on Formvar-coated single slot grids, and stained with uranyl acetate, followed by alkaline lead citrate. Ultrastructural analyses were performed in a Philips CM100 transmission electron microscope.

Acidification assay. Immunoisolated vesicles were eluted in $100 \mathrm{~mm}$ citrate, $\mathrm{pH} 2.5$, for $45 \mathrm{~min}$ and resuspended in acidification assay buffer $2 \times$ to get a final buffer composition of $10 \mathrm{~mm}$ HEPES-KOH, $\mathrm{pH} 7.4,4 \mathrm{~mm} \mathrm{KCl}, 4 \mathrm{~mm} \mathrm{MgSO}_{4}$, and $0.32 \mathrm{M}$ sucrose. The acidification assay was performed by measuring the fluorescence quenching of acridine orange (AO; Invitrogen) (Maycox et al., 1988). The reaction was started by adding $10 \mathrm{~mm} \mathrm{MgATP}$ in a stirred microcuvette containing $50 \mu \mathrm{l}$ of vesicles and $20 \mu \mathrm{M} \mathrm{AO}$, equilibrated at $32^{\circ} \mathrm{C}$. The reaction was stopped after $15-20 \mathrm{~min}$ by adding $50 \mathrm{~mm}\left(\mathrm{NH}_{4}\right)_{2} \mathrm{SO}_{4}$ to dissipate the proton gradient across the vesicular membrane and release AO from the vesicular lumen. Changes of fluorescence were analyzed using a Photon Technology International spectrofluorimeter (excitation, $490 \mathrm{~nm}$; emission, $530 \mathrm{~nm}$ ). The acidification kinetics were analyzed using Felix32 software (Photon Technology International) for acquisition of AO fluorescence and Prism4 (GraphPad Software) for kinetics and statistical analysis. Traces were normalized to the fluorescence at $t=0$ and corrected for baseline shifts induced by volume changes associated with the additions.

Uptake of radiolabeled amino acids. Amino acid uptake inside immunoisolated vesicles was analyzed by a filtration assay with radiolabeled amino acids as described previously (Burger et al., 1991). One-hundred-microliter aliquots of Sb2-immunoisolated beads resuspended in assay buffer $\left(0.32 \mathrm{M}\right.$ sucrose, $4 \mathrm{~mm} \mathrm{KCl,} 4 \mathrm{~mm} \mathrm{MgSO}_{4}$, and $10 \mathrm{~mm}$ HEPES-KOH, pH 7.4) were incubated with $400 \mu \mathrm{M}$ D-serine or $40 \mu \mathrm{M}$ L-glutamate containing $4 \mu \mathrm{Ci} \mathrm{D}-\left[{ }^{3} \mathrm{H}\right]$ serine or 2 $\mu \mathrm{Ci} \mathrm{L-}\left[{ }^{3} \mathrm{H}\right]$ glutamate (PerkinElmer Life and Analytical Sciences).
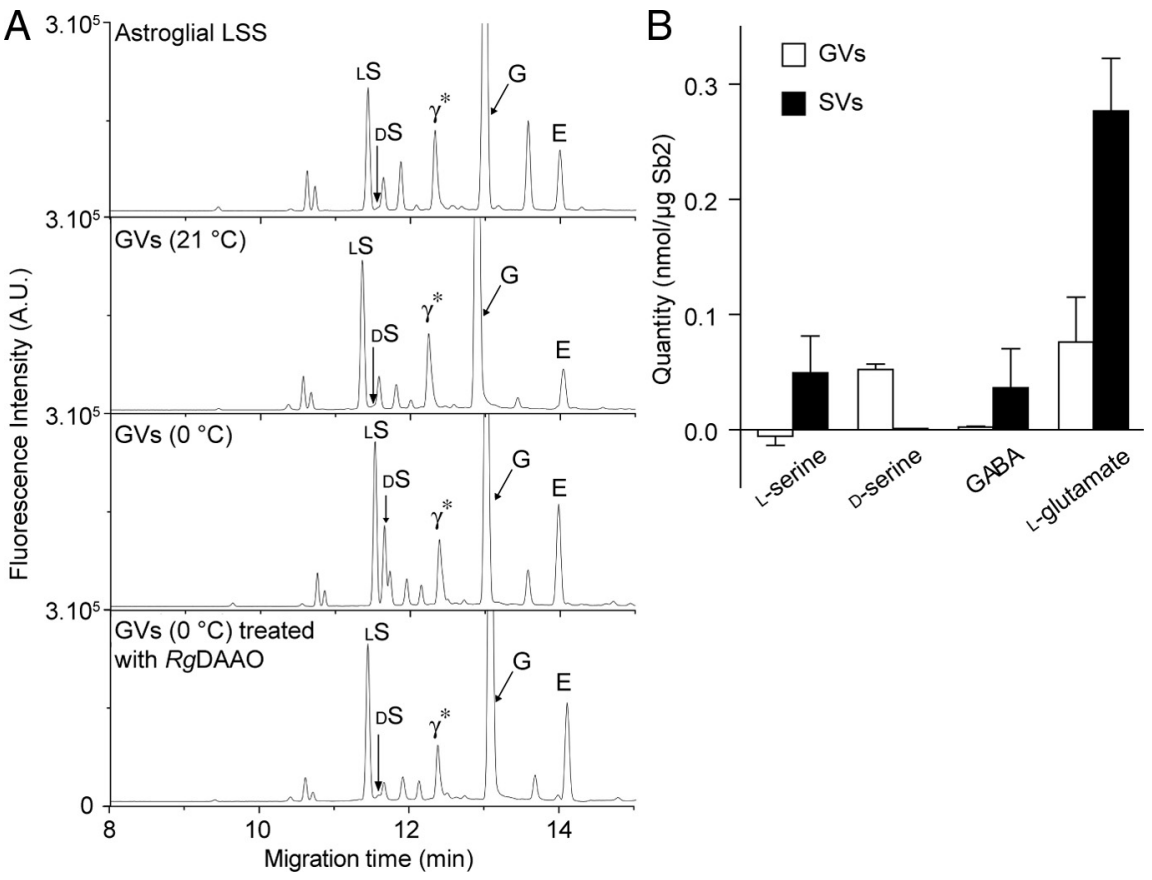

Figure 3. Amino acid content of immunoisolated GVs and SVs. A, Astroglial LSS, Sb2-containing vesicles immunoisolated at $21^{\circ} \mathrm{C}$ and $0^{\circ} \mathrm{C}$ with or without $\mathrm{RgDAAO}$ treatment were analyzed by CE. Electropherograms are adjusted to the same scale to independent experiments, normalized to $\mathrm{Sb} 2$ as a vesicle marker.

Uptake activities were assayed by rapid filtration on glass fiber filters (GF/C) using a cell harvester system (Connectorate) and by scintillation counting.

Determination of amino acid vesicular content. Immunoisolation was performed at $0^{\circ} \mathrm{C}$ to prevent vesicular content leakage (Burger et al., 1991). Starting material and immunoisolates were treated with 5\% $(\mathrm{w} / \mathrm{v})$ trichloroacetic acid to extract free amino acids as described previously (Hashimoto et al., 1992). Amino acids were determined by a laboratory-assembled capillary electrophoresis with laser-induced fluorescence (CE-LIF) system (Scanlan et al., 2010) using pre-column derivatization with $10 \mathrm{~mm}$ naphthalene-2,3-dicarboxaldehyde and 20 $\mathrm{mm} \mathrm{KCN}$ for $20 \mathrm{~min}$ in the dark. Chiral separation and quantitation were achieved by using a separation buffer consisting of $10 \mathrm{~mm}$ $\gamma$-cyclodextrin, $30 \mathrm{~mm}$ SDS, and $75 \mathrm{~mm}$ borate buffer at $\mathrm{pH} 10.5$. In addition, both a CE-LIF separation with non-chiral separation conditions (50 $\mathrm{mm}$ borate buffer at $\mathrm{pH}$ 8.42) and capillary electrophoresis-mass spectrometry (CE-MS) were used to verify analyte identifications and quantitation. The laboratory-assembled CE-MS instrument and separation conditions were as described previously (Lapainis et al., 2009; Nemes et al., 2011). Amino acid contents were corrected for nonspecific adsorption on beads determined by isolating vesicles at $21^{\circ} \mathrm{C}$ and normalized to $\mathrm{Sb} 2$ quantified by immunoblotting.

Immunostainings. Astrocytes cultured on glass coverslips were immunostained with pairs of antibodies as described previously (Martineau et al., 2008). Immunostainings of cerebral cortex with rabbit polyclonal anti-D-serine antibody was performed as described previously (Puyal et al., 2006) on $30 \mu \mathrm{m}$ coronal brain sections of 2-month-old male rats. Images were acquired using a confocal microscope (Leica TCS SP2), and colocalization was quantified using NIH ImageJ software as described previously (Martineau et al., 2008).

Statistical analyses. Uptake and acidification kinetics were analyzed using Prism4 software (GraphPad Software). Results are reported as mean \pm SEM from three to six independent experiments. Statistical significance was defined at $p<0.05$ using the Student's $t$ test. 


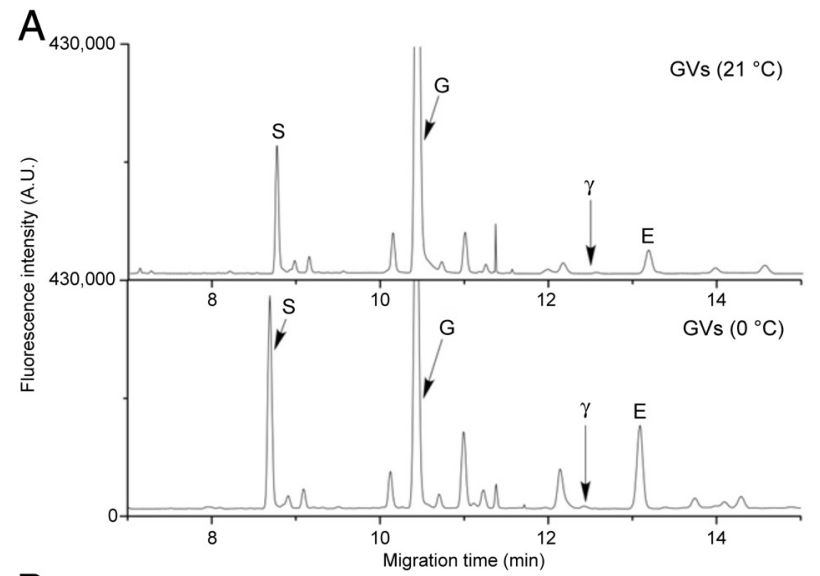

B

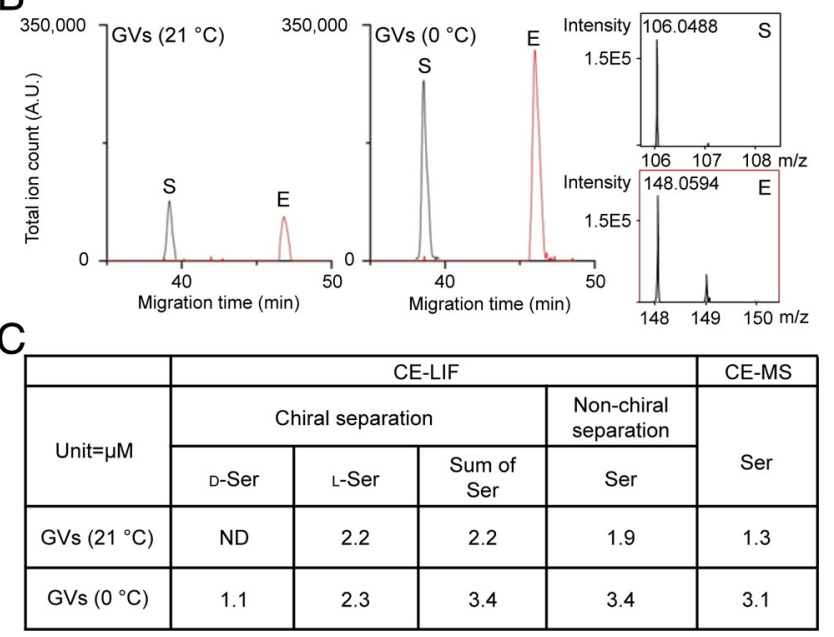

Figure 4. Quantitation of vesicle amino acid content using CE-LIF and CE-MS. To validate quantitation via $\mathrm{CE}-\mathrm{LIF}$ chiral separations as shown in Figure $3 A$, two additional measurements using non-chiral separation conditions were performed using CE-LIF and CE-MS detection to validate the quantitative measures and peak assignments. $A$, Astroglial Sb2-containing vesicles immunoisolated at $21^{\circ} \mathrm{C}$ and $0^{\circ} \mathrm{C}$ were analyzed using a non-chiral CE-LIF separation. Arrows point to the serine (S), GABA $(\gamma)$, glycine $(G)$, and glutamate (E) peaks. $B$, The same samples were analyzed by $C E-M S$. Electropherograms were adjusted to the same scale to facilitate comparison between approaches. $C$, A table shows representative quantification results of serine using these three different methods.

\section{Results}

\section{Glial Sb2-containing vesicles are similar to SVs}

Although D-serine was originally shown to be present in brain astrocytes (Schell et al., 1995; Panatier et al., 2006; Williams et al., 2006), recent investigations have revealed that both D-serine and its synthesizing enzyme SR are also present in neurons (Kartvelishvily et al., 2006; Miya et al., 2008). Therefore, to clarify the respective contribution of astrocytes and neurons in D-serine disposition in the mature rat cerebral cortex, we performed immunostainings for D-serine. Double immunostainings for D-serine with the astroglial marker glutamine synthase in situ revealed that $\mathrm{D}$-serine is mainly present in the soma and processes of astroglia (Fig. 1A). The amino acid is uniformly distributed among glial cells, whereas double immunostainings with the panneuronal marker $\beta 3$-tubulin indicated a moderate and uneven presence of D-serine in neuron soma and dendrites (Fig. 1A). Preembedding immunoperoxidase electron microscopy shows that $\mathrm{D}$-serine is enriched in glial processes apposed to excitatory synapses but is absent from presynaptic terminals and postsynaptic dendritic spines (Fig. 1B). Negative controls using a preab- sorbed anti-D-serine polyclonal antibody did not show any peroxidase staining (Fig. 1C).

$\mathrm{Ca}^{2+}$-dependent exocytosis of gliotransmitters, such as D-serine and L-glutamate, requires their compartmentalization into secretory organelles. As mentioned above, we showed previously that D-serine colocalizes with Sb2 (Martineau et al., 2008), raising the possibility that $\mathrm{D}$-serine is stored in such vesicles within astrocytes. To test whether such vesicles are indeed capable of storing and/or transporting gliotransmitters, we immunoisolated Sb2-containing organelles from an LSS of cultured astrocytes using beads coated with a monoclonal antibody specific for the cytoplasmic part of the SNARE protein Sb2 (Crippa et al., 2006; Martineau et al., 2008). Electron microscopy analysis revealed that the immunoisolated organelles mainly consist of small, clear vesicles with a homogeneous size distribution (40 \pm $16 \mathrm{~nm}$ ) (Fig. $2 A, B$ ). Thus, these isolated GVs are similar in size and morphology to GVs and SVs observed in situ (Harris and Sultan, 1995; Bezzi et al., 2004; Bergersen et al., 2012). Control beads coupled to non-immune IgG were devoid of bound membranes, suggesting that nonspecific contamination by other membranes is negligible. We next resolved the protein composition of immunoisolated GVs by immunoblotting (Fig. $2 C-E$ ). No signal for $\mathrm{Sb} 2$ was observed in control bead fractions. The immunoisolated organelles were devoid of the SV markers synaptophysin and synaptotagmin 1, excluding any contamination by SVs (Fig. 2D). GVs contain vesicular membrane proteins, such as the SNARE protein cellubrevin, the V-ATPase, SV2, and vGlut2 (Fig. $2 E)$. The immunoisolates were virtually free of contamination by plasma membranes and other endomembranes (Fig. 2E) as evident from the absence of signals for $\mathrm{Na}^{+}-\mathrm{K}^{+}$ATPase and SNAP23 (plasma membrane), PDI (endoplasmic reticulum), GM130 (Golgi apparatus), EEA1 and TfR (endosomes), cathepsin D (lysosomes), and PMP70 (peroxisomes).

\section{Purified GVs contain endogenous D-serine and L-glutamate}

We next investigated whether purified GVs contain amino acids. Capillary electrophoresis coupled to fluorescence detection revealed that $\mathrm{GVs}$ immunoisolated at $0^{\circ} \mathrm{C}$ contained $\mathrm{D}$-serine and L-glutamate in amounts that were much higher than in vesicles immunoisolated at $21^{\circ} \mathrm{C}$ or in control incubations (Fig. 3; corrected vesicular amount of $\mathrm{D}$-serine, $0.052 \pm 0.005 \mathrm{nmol} / \mu \mathrm{g} \mathrm{Sb} 2$; L-glutamate, $0.076 \pm 0.039 \mathrm{nmol} / \mu \mathrm{g} \mathrm{Sb} 2)$. This agrees with previous reports showing that amino acid neurotransmitters are only preserved inside SVs when isolated at $0^{\circ} \mathrm{C}$ (Burger et al., 1991). Although GABA has been reported to be released by astroglia (Angulo et al., 2008), we could not detect significant amount of GABA in GVs, suggesting its release from a cytosolic pool. To further confirm the identity of D-serine, we used conversion of D-serine by Rhodotorula gracilis D-amino acid oxidase (RgDAAO) (Mothet et al., 2005) (Fig. 3A). The quantifications of serine and glutamate were also confirmed using capillary electrophoresis separation under non-chiral conditions, followed by both fluorescence and mass spectrometry detections (Fig. 4).

To evaluate the physiological relevance of these results obtained on purified GVs, we investigated the presence of both GVs and D-serine on preembedded cerebral cortex preparations. Electron microscopy revealed the existence of clear round-shaped organelles (i.e., vesicle-like structures) in glia processes (Fig. 5A). Preembedding immunogold stainings revealed that $\mathrm{D}$-serine was associated with these vesicle-like structures in astrocytic processes facing asymmetric synapses (Fig. 5A). No immunogold particles were observed in neuronal boutons (Fig. 5A) and in 

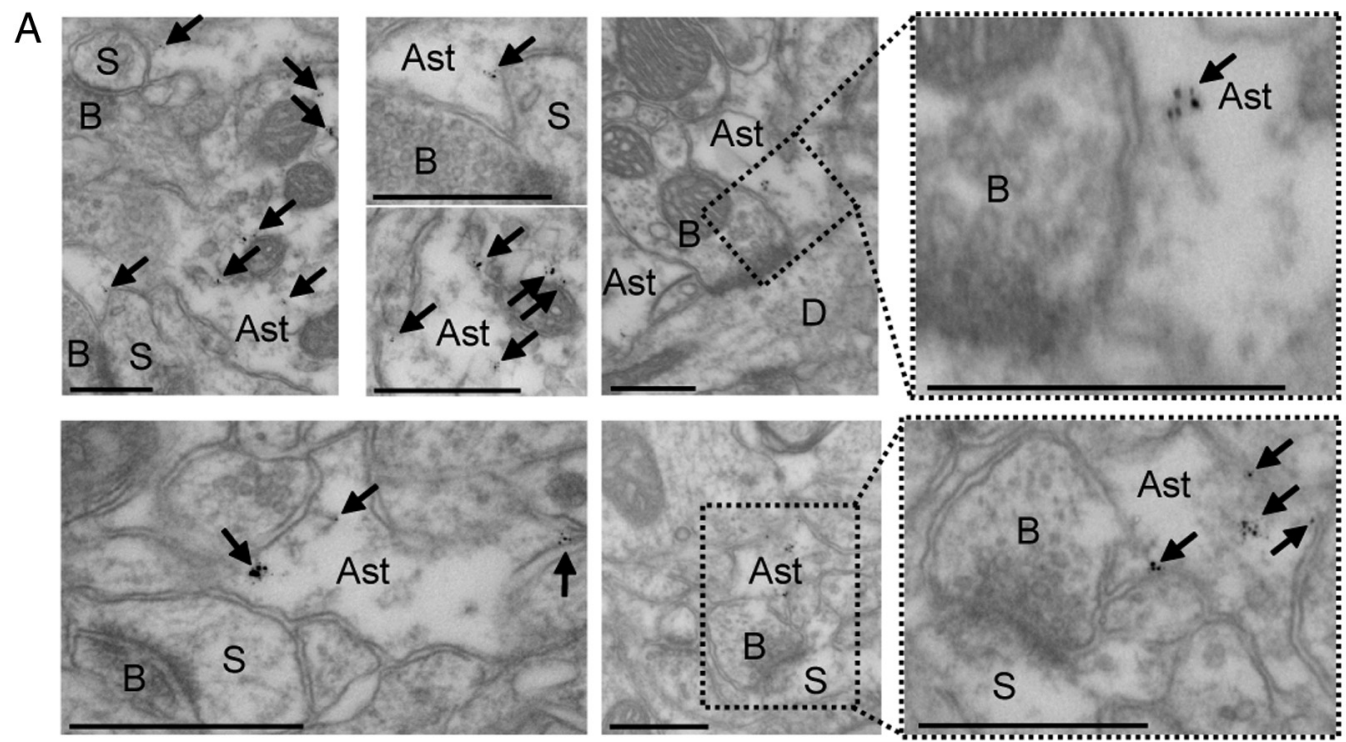
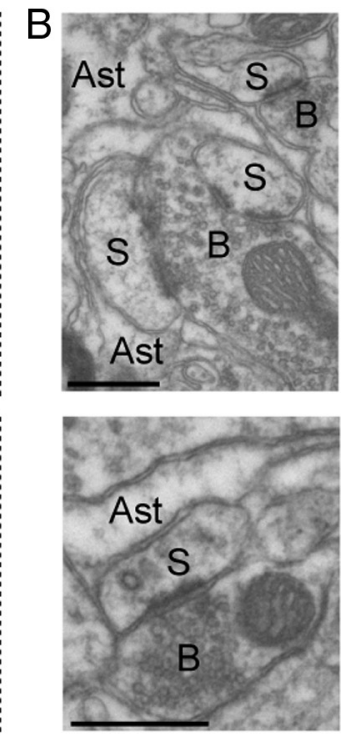

Figure 5. Preembedding immunogold staining for D-serine at glia-neuron interfaces in rat cerebral cortex. $\boldsymbol{A}$, Low-magnification shows that immunogold-positive particles (arrows) are detected in astrocytic processes surrounding asymmetric synapses. High magnifications reveal that D-serine is associated with vesicle-like structures located in astrocytic processes facing the asymmetric synapses. Please note that the insets are rotated compared with the low-magnification image. $\boldsymbol{B}$, Representative low-magnification (top) and high-magnification (bottom) electron micrographs showing that no immunogold-positive particle is detected with a preabsorbed anti-D-serine antibody. Ast, Astrocyte; D, dendrite; S, dendritic spine; B, axonal bouton. Scale bars, $500 \mathrm{~nm}$.

control conditions when brain slices were incubated with a preabsorbed anti-Dserine polyclonal antibody (Fig. 5B).

Cortical neurons also have been reported to release D-serine (Kartvelishvily et al., 2006; Rosenberg et al., 2010). Therefore, SVs from the whole rat cerebral cortex were isolated following the same procedure. As expected (Takamori et al., 2006), Sb2-containing SVs express major SV proteins, such as synaptophysin, V-ATPase, and synaptotagmin 1 (Fig. 6A). In agreement with previous work (Burger et al., 1991), SVs contain L-glutamate, glycine, and GABA (Figs. 3, 6B). However, D-serine was not detected, although it is present in the cortex homogenate (Figs. 3, 6B), supporting the notion that neurons do not exocytose D-serine but release it from a cytosolic pool (Kartvelishvily et al., 2006; Rosenberg et al., 2010). These results agreed with our observations that neuronal D-serine immunostaining was confined to the soma of neurons but was excluded from their distal neurites or boutons (Figs. 1, 5).

\section{Vesicular D-serine uptake is dependent on chloride concentration and is specific to astroglia}

The presence of D-serine in GVs suggests that GVs possess a specific transporter for this gliotransmitter. Properties of vesicular transporters have been mainly studied in purified SV fractions. All of them are driven by a proton electrochemical potential $\left(\Delta \mu \mathrm{H}^{+}\right)$generated by a V-ATPase (Edwards, 2007). We therefore examined whether GVs are capable of transporting $D$-serine in the presence of a proton electrochemical gradient. As shown in Figure 7A, this is indeed comparison with GVs.
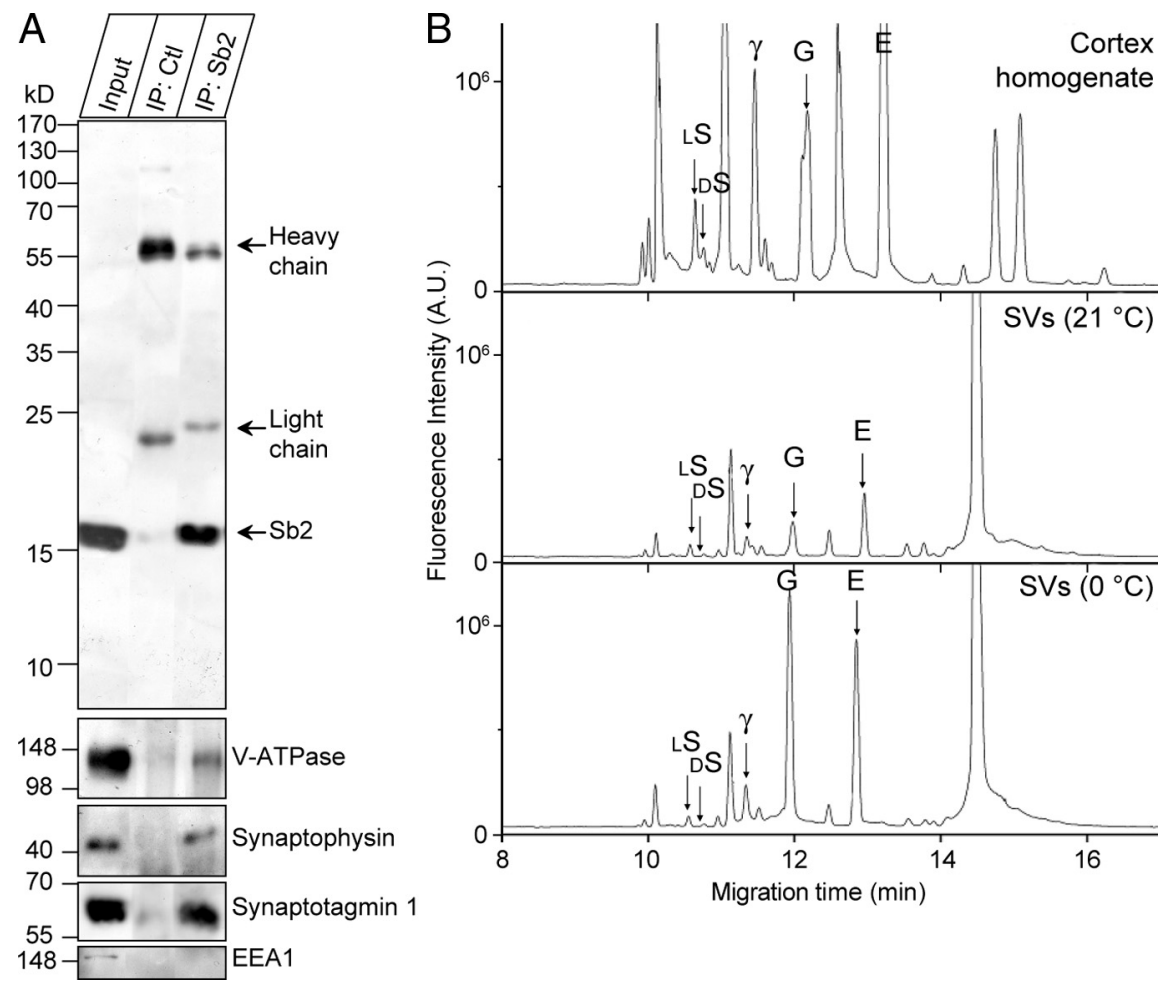

Figure 6. Characterization of immunoisolated SVs. A, Cortex homogenate (Input) and bead-bound material (IP) were immunoblotted for Sb2, V-ATPase (subunit a1), synaptophysin, synaptotagmin 1, and for the endosomal marker EEA1. Equal proportion of samples was loaded to allow direct comparison. Light and heavy chains correspond to light and heavy chains of antibodies. $\mathrm{Ctl}$, Control. B, Cortex homogenate, Sb2-containing SVs immunoisolated at $21^{\circ} \mathrm{C}$ and $0^{\circ} \mathrm{C}$ were analyzed by CE-LIF. Electropherograms are adjusted to the same scale to facilitate the comparison between traces. Arrowheads point to the position of $\mathrm{L}$-serine (LS), D-serine (DS), GABA ( $\gamma$ ), glycine (G), and L-glutamate (E). Quantification of amino acid content in SVs is presented in Figure $3 B$ for

the case. Immunoisolated GVs showed ATP-dependent uptake of $\mathrm{D}-\left[{ }^{3} \mathrm{H}\right]$ serine that was blocked by the V-ATPase inhibitor bafilomycin and sensitive to the uncoupler FCCP (carbonyl cyanide $p$-trifluoromethoxyphenylhydrazone). 
A
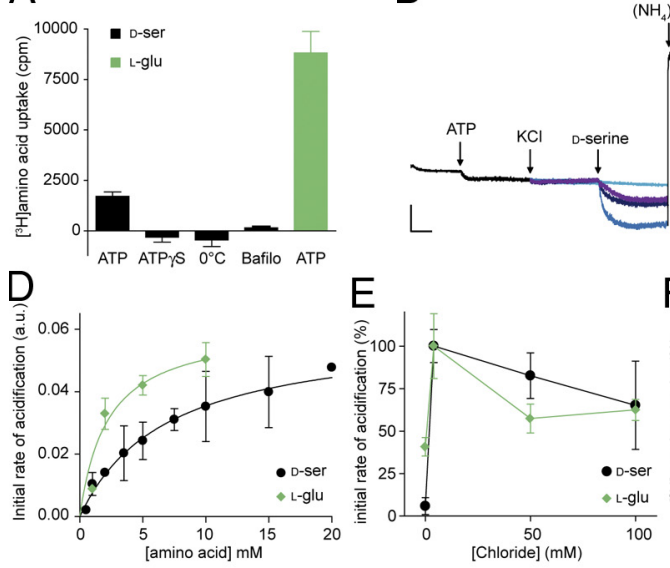

$\mathrm{F}$

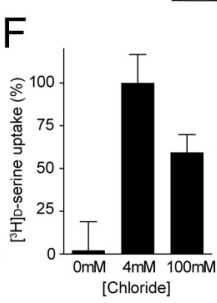

B

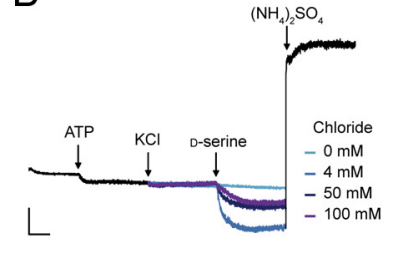

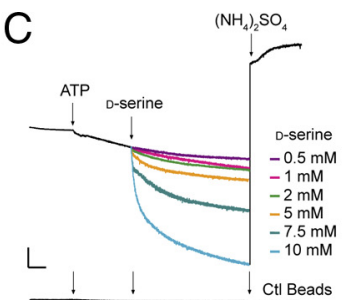

G

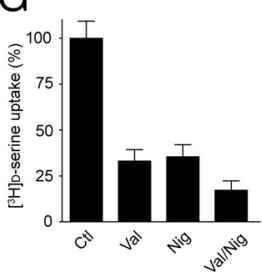

Figure 7. Features of vesicular D-serine uptake into astrocytic immunopurified vesicles. $A$, ATP-dependent uptake of $D$ - $\left[{ }^{3} \mathrm{H}\right]$ serine and $\mathrm{L}-\left[{ }^{3} \mathrm{H}\right] \mathrm{glutamate}$. The values represent $\mathrm{FCCP}$-sensitive uptake. FCCP $(40 \mu \mathrm{M})$ was added together with MgATP (4 $\mathrm{mm})$. Control experiments are performed by replacing MgATP by ATP $\gamma \mathrm{S}(4 \mathrm{mM})$, by decreasing temperature to $0^{\circ} \mathrm{C}$, or by inhibiting V-ATPase with bafilomycin A1 $(1 \mu \mathrm{m})$. B, D-Serine $(7.5 \mathrm{~mm})$-mediated acidification of GVs is dependent on chloride (the figure shows representative traces from 3-6 independent measurements). To maintain ionic strength and osmolarity, chloride was exchanged for gluconate (potassium salts). Arrows correspond to addition of the tested compound [10 mM ATP and $50 \mathrm{~mm}$ $\left(\mathrm{NH}_{4}\right)_{2} \mathrm{SO}_{4}$, final concentrations in this and the following figures]. At the end of the reaction, $\left(\mathrm{NH}_{4}\right)_{2} \mathrm{SO}_{4}$ was added to dissipate $\Delta \mathrm{pH}$. C, Overlay of photometric traces showing acidification of GVs induced by various D-serine concentrations in the presence of 4 $\mathrm{mm}$ chloride (representative of 3-5 independent experiments). No change in fluorescence under any condition was observed when control (Ctl) beads (mouse lgG) were used. Scale bars, 2 arbitrary units per $1 \mathrm{~min}$. $\boldsymbol{D}$, Dependence of the initial rate of acidification on D-serine and L-glutamate concentration. $\boldsymbol{E}, \boldsymbol{F}$, Initial rate of acidification induced by D-serine $(7.5 \mathrm{mM})$ or L-glutamate $(5 \mathrm{mM})$ and D- $\left[{ }^{3} \mathrm{H}\right]$ serine uptake were measured in the presence of different chloride concentrations. $G$, Influence of both components of the proton electrochemical potential $\Delta \mu \mathrm{H}^{+}$on FCCP-sensitive ATP-dependent D- $\left[{ }^{3} \mathrm{H}\right]$ serine uptake. Additions: $5 \mu \mathrm{m}$ nigericin (Nig), $20 \mu \mathrm{m}$ valinomycin (Val). Error bars represent mean $\pm \mathrm{SEM} ; n=3-6$ independent experiments.

Next, we tested whether the vesicles also transport glutamate as suggested by the presence of vGlut2 (Fig. 2) (Bezzi et al., 2004; Crippa et al., 2006). Again, ATP-dependent transport of L- $\left[{ }^{3} \mathrm{H}\right]$ glutamate was observed (Fig. $7 A$ ).

The proton electrochemical potential $\Delta \mu \mathrm{H}^{+}$has two components: the membrane electric potential $(\Delta \Psi)$ and the $\mathrm{pH}$ gradient $(\Delta \mathrm{pH})$. In SVs, the relative contribution of the two components is determined by the presence of chloride, which provides charge balance to $\mathrm{H}^{+}$(Edwards, 2007). To characterize the dependence of D-serine uptake by GVs on the components of $\Delta \mu \mathrm{H}^{+}$, we monitored vesicular acidification using the $\mathrm{pH}$-sensitive dye AO. Surprisingly, no ATP-dependent acidification was observed when $\mathrm{Cl}^{-}$was added up to a concentration of $100 \mathrm{~mm}$ (Fig. 7B), in contrast to SVs that show strong acidification in the presence of chloride (Hell et al., 1990; Schenck et al., 2009). Apparently, GVs are impermeant to $\mathrm{Cl}^{-}$. In contrast, addition of D-serine induced a dose-dependent acidification of GVs with a $K_{M}$ of 6.9 $\mathrm{mm}$ for the initial rate of acidification (Fig. $7 C, D$ ). However, D-serine-dependent acidification as well as D- $\left[{ }^{3} \mathrm{H}\right]$ serine uptake were completely dependent on the presence of chloride, with a maximum at $4 \mathrm{~mm}$ chloride that then declined slightly at higher chloride concentrations (Fig. $7 E, F$ ). These results indicate that, at least under these conditions, chloride provides charge balance for the protons during the uptake of $\mathrm{D}$-serine (which contains no net charge at neutral $\mathrm{pH}$ ), suggesting that $\mathrm{D}$-serine uptake is coupled to chloride transport. Replacement of $\mathrm{K}^{+}$by $\mathrm{Na}^{+}$and of $\mathrm{SO}_{4}{ }^{2-}$ by gluconate shows no influence of these ions on the $\Delta \mathrm{pH}$ induced by D-serine (data not shown). The effect of chloride on the vesicular D-serine transport prompted us to assess the relative contribution of both components of the proton electrochemical potential $\Delta \mu \mathrm{H}^{+}$to the vesicular uptake of $\mathrm{D}$-serine. The $\mathrm{K}^{+}$ionophore valinomycin and the $\mathrm{K}^{+} / \mathrm{H}^{+}$exchanger nigericin selectively abolish with acidification (Fig. 8A), suggesting that glutamate serves as counterion for proton transport (Maycox et al., 1988; Schenck et al., 2009). However, glutamate uptake is also dependent on the presence of chloride. Because chloride on its own induces strong acidification of SVs, it has been difficult to resolve to which extent the effects of chloride are direct (e.g., as activator of vGlut activity) or indirect by shifting the balance between $\Delta \Psi$ and $\Delta \mathrm{pH}$, and the role of chloride in activation and the transport cycle of vGluts is controversial (Schenck et al., 2009; Juge et al., 2010). Similar to SVs (Fig. 8A), glutamate induced acidification of GVs (Fig. 7D). The apparent $K_{M}$ was $2.2 \mathrm{~mm}$, similar to that reported for SVs (Naito and Ueda, 1985; Maycox et al., 1988), with the maximal rate being comparable with that induced by D-serine (Fig. $7 D$ ). Similar to D-serine, chloride has a biphasic effect on L-glutamate transport, with activation at low concentrations (4 mM) and inhibition at high concentrations (>50 mM) (Fig. 7E), resembling previous reports from SVs (Hell et al., 1990; Schenck et al., 2009). In contrast to D-serine-induced acidification, significant uptake was already measured in the absence of chloride. However, the inhibition at high chloride concentrations is weaker in GVs than that reported for SVs (Hell et al., 1990; Schenck et al., 2009). This discrepancy may be attributable to the lack of chloride permeability of GVs that thus cannot dissipate $\Delta \Psi$, the component of the electrochemical potential fuelling glutamate uptake (Hell et al., 1990; Schenck et al., 2009).

\section{D-Serine and L-glutamate vesicular loading exert mutual stimulation}

D-Serine and L-glutamate are both stored and transported inside GVs. vGluts have been shown to enhance vesicular loading of GABA and monoamines in nonglutamatergic neurons through a process called vesicular synergy (for review, see El Mestikawy et 


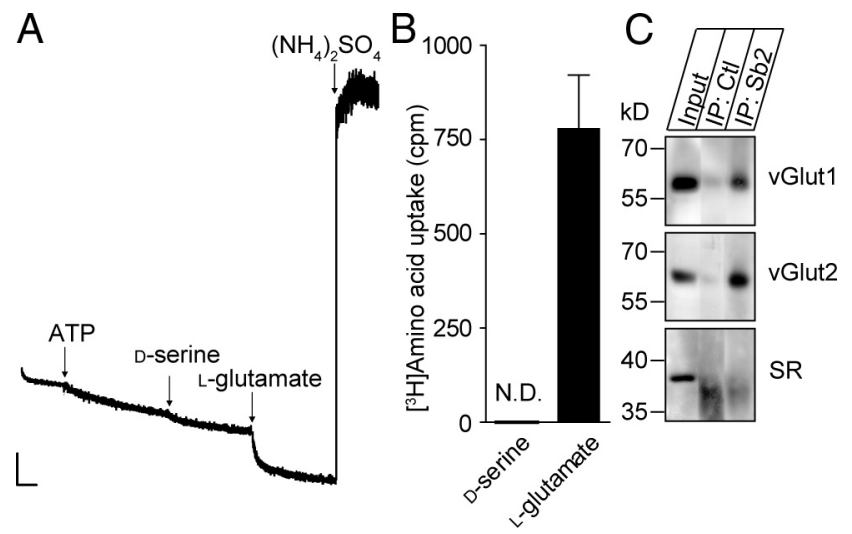

Figure 8. SVs transport L-glutamate but not D-serine. $\boldsymbol{A}$, Photometric trace showing the absence of $D$-serine-induced acidification of SVs, whereas L-glutamate can acidify these organelles (10 mm each, $n=3$ ). Scale bar, 2 arbitrary units per $1 \mathrm{~min}$. $\boldsymbol{B}$, ATP-dependent uptake of D- $\left[{ }^{3} \mathrm{H}\right]$ serine and $\mathrm{L}-\left[{ }^{3} \mathrm{H}\right]$ glutamate by isolated SVs. The values represent FCCP-sensitive uptake. N.D., Not detectable. Values represent mean \pm SEM of two independent experiments performed in triplicate. C, Western blot analysis of cortex homogenate (Input) and control (Ctl) or Sb2 immunoisolates (IP) for vGlut1 and vGlut2 and for SR.
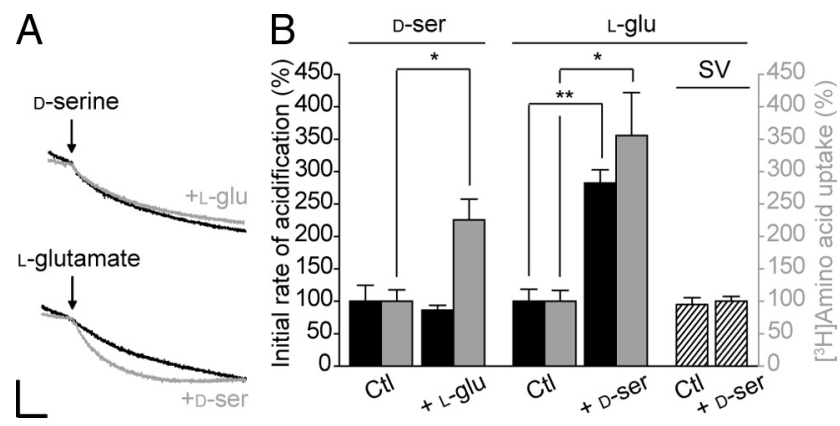

Figure 9. Vesicular synergy between D-serine and L-glutamate transport activities in GVs. $\boldsymbol{A}$, Partial photometric traces showing the acidification induced by $5 \mathrm{~mm}$ D-serine (top) and $5 \mathrm{~mm}$ L-glutamate (bottom) in the absence (black) or presence (gray) of $5 \mathrm{~mm}$ L-glutamate and 5 mM D-serine, respectively. The experiments were performed as in Figure 7, i.e., initiated with 10 mм ATP and ended with $50 \mathrm{~mm}\left(\mathrm{NH}_{4}\right)_{2} \mathrm{SO}_{4}$. Scale bar, 2 arbitrary units per $1 \mathrm{~min}$. $\boldsymbol{B}$, Histogram showing the reciprocal effect of each amino acid (D-serine or L-glutamate) on the acidification rate and uptake of the other one. Amino-acid-induced acidification was measured as in $\boldsymbol{A}$. FCCP-sensitive ATP-dependent uptakes of $\mathrm{L}-\left[{ }^{3} \mathrm{H}\right]$ glutamate or $\mathrm{D}-\left[{ }^{3} \mathrm{H}\right]$ serine were measured in the presence of $10 \mathrm{~mm}$ D-serine or L-glutamate, respectively. $\mathrm{Ctl}$, Control. Error bars represent mean $\pm \mathrm{SEM} ; n=3$ for acidification, 4 in duplicate for radioactive assay. ${ }^{*} p<0.05,{ }^{* *} p<$ 0.01 , Student's $t$ test.

al., 2011). Such vesicular synergy has not yet been described for gliotransmitters. Therefore, we investigated whether both amino acids could be present in the same GVs and to what extent L-glutamate is able to modulate the accumulation of D-serine inside GVs and vice versa. To this end, the acidification induced by one amino acid was measured in the presence or absence of the other. Under standard conditions, the D-serine-induced acidification was unaffected by the presence of L-glutamate. On the contrary, $5 \mathrm{mM}$ D-serine markedly accelerates to $\sim 280 \%$ the initial rate of acidification induced by L-glutamate (Fig. $9 A, B$ ). To determine whether the vesicular acidification rate reflects the amino acid accumulation, we measured the transport of $\mathrm{L}-\left[{ }^{3} \mathrm{H}\right]$ glutamate in $\mathrm{GVs}$ for $10 \mathrm{~min}$ in the presence of $10 \mathrm{~mm}$ $\mathrm{D}$-serine and vice versa. Consistent with the acidification assay, FCCP-sensitive L- $\left[{ }^{3} \mathrm{H}\right]$ glutamate uptake by GVs was reproducibly increased by $\sim 350 \%$ in the presence of D-serine (Fig. $9 B$ ). Conversely, L-glutamate had a slightly smaller stimulatory effect $(\sim 225 \%)$ on $\mathrm{D}-\left[{ }^{3} \mathrm{H}\right]$ serine uptake, which was not revealed by the indirect measure of the initial rate of loading. The interplay between D-serine and L-glutamate uptakes may reflect their common dependency on chloride. However, the influence on the loading rate and amplitude exerted by one amino acid on the other is not absolutely symmetrical. Because L-glutamate uptake relies mostly on $\Delta \Psi$ whereas D-serine uptake depends more equally on both $\Delta \Psi$ and $\Delta \mathrm{pH}$, this discrepancy may be attributable to their bioenergetic properties.

SVs are devoid of any transport activity for D-serine (Fig. 8). Therefore, to finally address whether the stimulation of vesicular L-glutamate transport by D-serine is attributable to the presence or the transport of the amino acid, we analyzed the effect of 10 $\mathrm{mM}$ D-serine on L-glutamate loading inside SVs. In contrast to GVs, D-serine had no effect on L-glutamate uptake in SVs, excluding a direct action of D-serine on vGlut but rather suggesting a synergic effect of D-serine uptake on vGlut activity (Fig. 9B).

\section{Uptake of newly synthesized D-serine is coupled to the activity} of GV-associated SR

To characterize the substrate stereoselectivity of D-serine transport, we investigated the effect of L-serine on GV acidification. Addition of L-serine induced acidification of GVs with an initial rate of acidification comparable with that of D-serine (Fig. $10 A, C)$, suggesting that the vesicular transporter does not discriminate between the enantiomers. However, L-serine is not retrieved in isolated GVs (Fig. 3). In addition, L-serine did not further induce acidification when GVs were preloaded with D-serine and vice versa (data not shown). We therefore tested whether L-serine is first converted to D-serine by SR. Whereas SR is reported to be principally cytosolic (Balan et al., 2009), confocal microscopy analysis revealed a particulate staining pattern, displaying significant colocalization between SR and Sb2 in cultured astrocytes from rat brain cortex $(20.6 \pm 8.9 \%$ Sb2 vs SR, $25.2 \pm 11.5 \%$ SR vs Sb2) (Fig. 10B), similar to the colocalization between D-serine and Sb2 (Martineau et al., 2008). Immunoblotting then revealed that SR is present in purified GVs (Fig. 10B) but absent from SVs (Fig. 8C). Thus, SR appears to be anchored to $\mathrm{Sb} 2$-containing GVs, suggesting that L-serine is converted to D-serine that is then transported into GVs. Such a vesicular localization may guarantee local high concentrations of the substrate, which may be advantageous for efficient transport of this gliotransmitter. Indeed, incubation of GVs with a potent competitive inhibitor of SR, L-erythro-3-hydroxyaspartate (HOAsp) (Strísovský et al., 2005), strongly reduced L-serine-induced acidification without affecting the acidification induced by D-serine (Fig. 10C,D). Because the acidification kinetics measured for L-serine and D-serine without HOAsp are identical, neither newly synthesized nor preexisting D-serine is taken up preferentially. Finally, similar to vGluts (Naito and Ueda, 1985), the transporter for D-serine is stereoselective.

\section{Discussion}

In this study, we isolated and characterized a population of small, clear vesicles from astrocytes with both morphological and biochemical features reminiscent of neuronal SVs. We show that these vesicles contain the endogenous gliotransmitters D-serine and L-glutamate and possess specific transport activities for these transmitters. We further characterized the properties of D-serine uptake and found that this transport activity is specific for astroglia, associated with vesicle acidification, dependent on chloride, and is stereoselective. Although D-serine synthesizing enzyme SR is present at the membrane of GVs, we observed a functional coupling between SR activity and D-serine vesicular transport. 
A
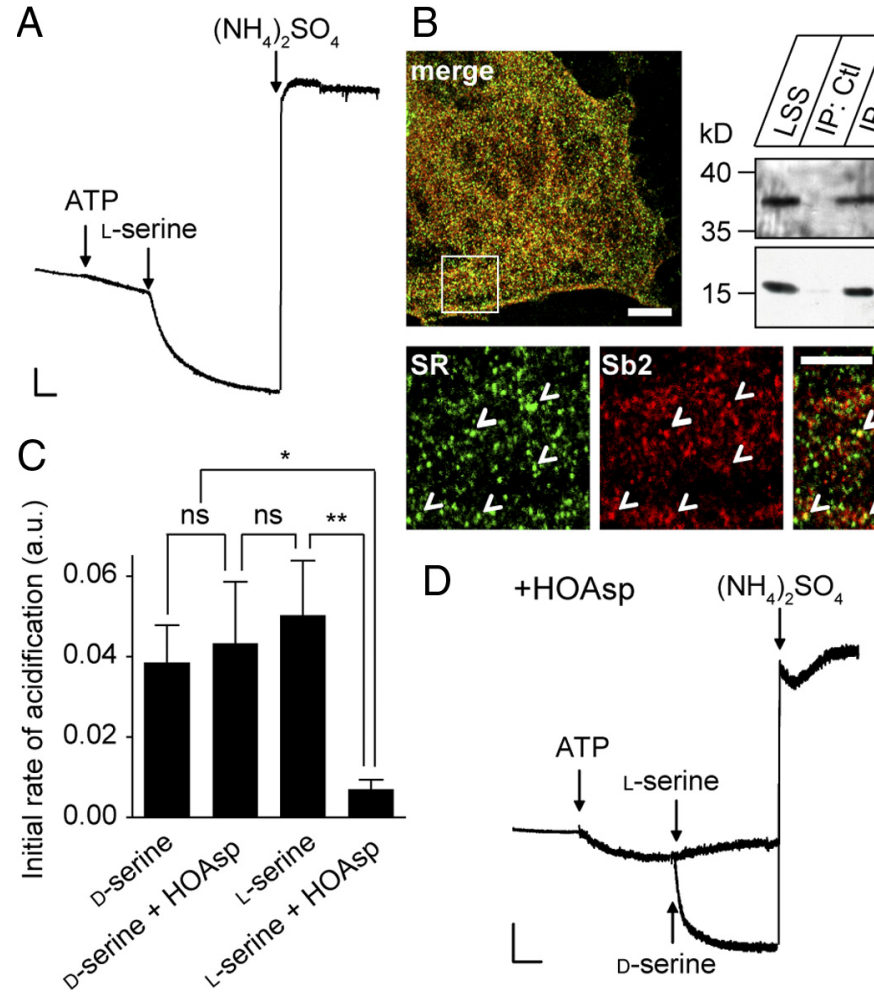

Figure 10. D-Serine uptake by immunoisolated GVs is coupled to endogenous SR activity. $A$, Photometric trace showing acidification induced by $10 \mathrm{~mm} \mathrm{~L}$-serine (representative trace from 4 independent experiments). Scale bar, 2 arbitrary units per $1 \mathrm{~min}$. $\boldsymbol{B}$, Colocalization of SR (green) with Sb2 (red) in cultured astrocytes. Scale bars: top (low magnification), $10 \mu \mathrm{m}$; bottom (high magnification), $5 \mu \mathrm{m}$. The presence of SR on GVs is confirmed by immunoblotting of immunoisolated GV fractions. Ctl, Control. C, $D$, Inhibition of SR by HOAsp (400 $\mu \mathrm{m}, 10 \mathrm{~min}$ ) abolishes L-serine-induced acidification without affecting D-serine-induced acidification (10 mm each, representative traces from 4-5 independent experiments). Scale bars, 2 arbitrary units per $1 \mathrm{~min}$. ns, Not significant, ${ }^{*} p<0.05,{ }^{* *} p<0.01$, Student's $t$ test.

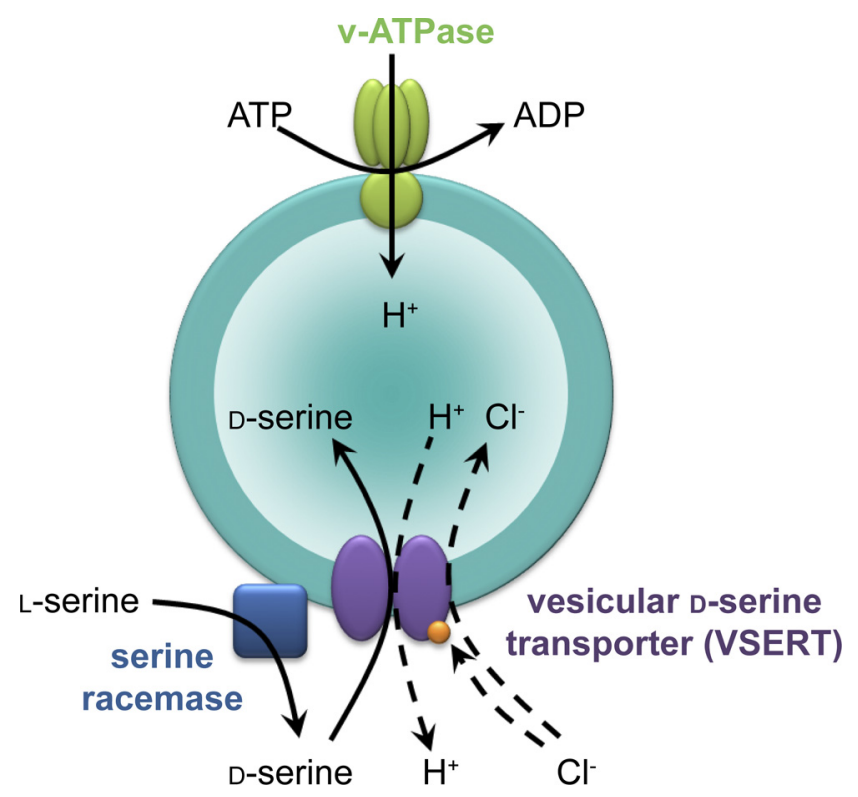

Figure 11. VSERT operates as a putative $\mathrm{D}-$ serine/ $\mathrm{H}^{+}$antiporter with a chloride leak or a coupled chloride cotransport. Although $\mathrm{D}$-serine is a neutral amino acid, chloride acts as a counterion for V-ATPase and increases the $\mathrm{pH}$ gradient while reducing the membrane potential. Alternatively, chloride could modulate D-serine transport by regulatory binding to the transporter. SR is anchored to the membrane of GVs in which it converts L-serine into D-serine, allowing a local and efficient concentration of the gliotransmitter to be transported. However, preexisting D-serine is also taken up in GVs without any preference over a newly synthesized one.
Finally, we provided evidence for an unexpected vesicular synergy between D-serine and L-glutamate uptake in astrocytes. Together, our findings lend strong support to the view that both L-glutamate and D-serine are released from astroglia by exocytosis from storage organelles with properties reminiscent of neuronal SVs.

The small vesicles immunoisolated from rat cortical astrocytes in culture share morphological and molecular properties with vesicles previously characterized from astrocytes in situ using immunocytochemistry and immunoelectron microscopy, notably their homogenous size $(\sim 40 \mathrm{~nm}$ in diameter), round shape, clear appearance, and presence of vGlut and SNARE proteins (Bezzi et al., 2004; Bergersen et al., 2012). It suggests that the vesicles isolated and characterized by us do indeed correspond to the GVs described previously. The morphological properties of GVs are also similar to those of SVs (Harris and Sultan, 1995; Bergersen et al., 2012). Apparently, the two organelles also share some of the major proteins, including Sb2, the V-ATPase, vGlut2, and SV2. However, other major SV proteins (such as synaptophysin and synapsins) are known to be absent from glial cells, and additional work, involving quantitative comparisons of major proteins, is required to assess similarities and differences in the protein composition. Most importantly, the subcellular distribution clearly distinguishes GVs from SVs. According to electron microscopy analyses, GVs are far less abundant in astroglial processes than SVs in synaptic boutons. The dominance of SVs in the neuropil may explain why the presence of vesicular proteins in astroglia has been difficult to demonstrate in situ (Cahoy et al., 2008). The lower abundance of these organelles also required a modification of the immunoisolation protocol for GVs compared with SVs, involving upscaling of starting material, higher concentration of beads and coupled antibodies, and longer incubation times (see Materials and Methods).

In the present study, we show conclusively that two gliotransmitters, namely L-glutamate and D-serine, are stored inside GVs. However, these amino acids are retained by GVs only when isolated under appropriate conditions. Leakage of L-glutamate and $\mathrm{D}$-serine can be prevented or at least minimized when vesicle isolation is performed at $0^{\circ} \mathrm{C}$, in agreement with previously reports on SVs (Burger et al., 1991). We cannot exclude that even under these conditions some efflux of amino acids occurred. The actual vesicular content may thus be higher than that found in our experiments. Because we do not know the number of Sb2 copies per GV, it is not possible to provide an accurate estimate of the intravesicular concentration of these amino acids. Presently, we cannot exclude the presence of other small organic molecules in GVs as indicated by unidentified peaks in the electropherograms.

This is the first demonstration of a specific vesicular transporter for D-serine with features reminiscent of, but not identical to, the well-established vesicular transporters for excitatory and inhibitory amino acids. D-Serine is transported into GVs with an 
affinity similar to the affinity of the vesicular inhibitory amino acid transporter (VIAAT) for GABA (Christensen et al., 1991). Our work has revealed key features of D-serine vesicular transport: it is specific for astroglia, dependent on both components of $\Delta \mu \mathrm{H}^{+}$produced by a V-ATPase, associated with proton transport, and requires chloride for activation. Because D-serine has no net charge at neutral $\mathrm{pH}$ and chloride is required for vesicular acidification induced by $\mathrm{D}$-serine, we propose that chloride provides charge balance while being cotransported with $\mathrm{D}$-serine in a coupled or uncoupled manner. A coupled transmitter/chloride cotransport mechanism has already been proposed for VIAAT (Juge et al., 2009). Alternatively, VSERT may harbor an uncoupled anion conductance activated by substrates, as reported for plasma membrane glutamate transporters (Fairman et al., 1995; Ryan and Mindell, 2007). Together, these data are compatible with a model in which the putative $\mathrm{D}$-serine transporter operates as a D-serine $/ \mathrm{H}^{+}$antiporter (Fig. 11). In addition, our study reveals that a spatial association of SR activity and D-serine vesicular transport results in a functional coupling between synthesis and uptake that has been described previously in SVs for GABA and dopamine (Chen et al., 2003; Jin et al., 2003; Cartier et al., 2010). The presence of SR at the membrane of GVs allows a local synthesis of D-serine and thus favors the efficient transport of the gliotransmitter. However, in contrast to GABA and dopamine (Chen et al., 2003; Jin et al., 2003), preexisting D-serine is taken up into GVs without any preference over a newly synthesized one. Therefore, it is unlikely that the activity of SR directly influences the transport activity for D-serine. Brain SR does not possess a transmembrane region (Balan et al., 2009). This is also the case for the tyrosine hydroxylase and glutamate decarboxylase, the synthesizing enzymes for GABA and dopamine. Intriguingly, these enzymes are associated with the respective storage vesicles, apparently by means of a specific interaction with the respective transporters (Jin et al., 2003; Cartier et al., 2010). It is conceivable that vesicle binding SR is also mediated by an interaction with VSERT, but for this issue to be addressed, the transporter needs to be identified. Previously, binding of SR to the plasma membrane of astrocytes and neurons has been described (Balan et al., 2009; Mustafa et al., 2009). This binding occurs through interaction with phosphatidylinositol (4,5)-biphosphate in astrocytes (Mustafa et al., 2009) or through posttranslational modifications in neurons (Balan et al., 2009) and leads to inactivation of the enzyme. In contrast, our data show that vesicle-bound SR is active, suggesting that the binding mechanism is different. Inactivation of SR at the plasma membrane may be a means to stop conversion of L-serine at the "wrong" place, i.e., after incorporation of the GV membrane into the plasma membrane after exocytosis.

The presence of vGluts and vesicular transport activity for L-glutamate has already been observed in astrocytes (Bezzi et al., 2004; Crippa et al., 2006; Bergersen et al., 2012). However, L-glutamate uptake inside GVs has not been fully characterized. In our study, we confirmed these previous reports and further analyzed the uptake properties of this amino acid inside GVs. We demonstrated that L-glutamate is transported by GVs with an apparent affinity and a biphasic chloride dependency similar to that reported for SVs (Naito and Ueda, 1985; Maycox et al., 1988). However, in contrast to SVs, we did not observe chloridedependent acidification, which is difficult to reconcile with vGlut2 functioning as a chloride channel as suggested recently for vGlut1 (Schenck et al., 2009). The lack of a transportindependent chloride conductance compensating for proton transport is a major distinguishing feature of GV versus SV transport, which requires additional investigation.

The storage and transport of both D-serine and L-glutamate in GVs raises the question of their possible costorage and thus corelease. Our vesicular content analyses (Figs. 3,4 ) do not allow us to distinguish between one population containing both gliotransmitters or two distinct populations dedicated to one gliotransmitter. Recently, immunogold colabeling of D-serine and L-glutamate in the adult hippocampus revealed that both amino acids are presumably stored in distinct vesicular pools (Bergersen et al., 2012). However, the limited sensitivity of the immunogold technique does not allow unequivocal conclusion. Here, we report that D-serine transport stimulates L-glutamate uptake in GVs, indicating a functional crosstalk between the two transporters that can only be explained by both transporters residing on the same vesicle. The mechanism underlying this vesicular synergy between both amino acid uptakes requires additional investigation. Whatever the mechanism, glial cytoplasmic D-serine when transported in GVs would be able to amplify L-glutamate-mediated gliotransmission. Interestingly, corelease of both gliotransmitters from the same vesicle would be a perfect combination for activating NMDA receptors. To our best knowledge, we provide the first experimental evidence for a cotransmitter action on vesicular glutamate uptake and extend the notions of both corelease and vesicular synergy beyond neurons. However, the existence of a population of GVs storing and releasing both D-serine and glutamate does not exclude the possibility of GVs loaded with one but not the other gliotransmitter.

In conclusion, our work supports the concept that astrocytes possess specific vesicles capable of sequestering and storing D-serine and L-glutamate as gliotransmitters, which undergo calcium-dependent exocytosis and modulate synaptic transmission. Additionally, the vesicular synergy unraveled in glial cells would represent a safe-cost metabolic process by reducing the energy demand of regulated exocytosis.

\section{References}

Angulo MC, Le Meur K, Kozlov AS, Charpak S, Audinat E (2008) GABA, a forgotten gliotransmitter. Prog Neurobiol 86:297-303. CrossRef Medline Araque A, Li N, Doyle RT, Haydon PG (2000) SNARE protein-dependent glutamate release from astrocytes. J Neurosci 20:666-673. Medline

Balan L, Foltyn VN, Zehl M, Dumin E, Dikopoltsev E, Knoh D, Ohno Y, Kihara A, Jensen ON, Radzishevsky IS, Wolosker H (2009) Feedback inactivation of D-serine synthesis by NMDA receptor-elicited translocation of serine racemase to the membrane. Proc Natl Acad Sci U S A 106: 7589-7594. CrossRef Medline

Bergersen LH, Morland C, Ormel L, Rinholm JE, Larsson M, Wold JF, Røe AT, Stranna A, Santello M, Bouvier D, Ottersen OP, Volterra A, Gundersen V (2012) Immunogold detection of L-glutamate and D-serine in small synaptic-like microvesicles in adult hippocampal astrocytes. Cereb Cortex 22:1690-1697. CrossRef Medline

Bezzi P, Gundersen V, Galbete JL, Seifert G, Steinhäuser C, Pilati E, Volterra A (2004) Astrocytes contain a vesicular compartment that is competent for regulated exocytosis of glutamate. Nat Neurosci 7:613-620. CrossRef Medline

Burger PM, Hell J, Mehl E, Krasel C, Lottspeich F, Jahn R (1991) GABA and glycine in synaptic vesicles: storage and transport characteristics. Neuron 7:287-293. CrossRef Medline

Cahoy JD, Emery B, Kaushal A, Foo LC, Zamanian JL, Christopherson KS, Xing Y, Lubischer JL, Krieg PA, Krupenko SA, Thompson WJ, Barres BA (2008) A transcriptome database for astrocytes, neurons, and oligodendrocytes: a new resource for understanding brain development and function. J Neurosci 28:264-278. CrossRef Medline

Cartier EA, Parra LA, Baust TB, Quiroz M, Salazar G, Faundez V, Egaña L, Torres GE (2010) A biochemical and functional protein complex involving dopamine synthesis and transport into synaptic vesicles. J Biol Chem 285:1957-1966. CrossRef Medline

Chen R, Wei J, Fowler SC, Wu JY (2003) Demonstration of functional cou- 
pling between dopamine synthesis and its packaging into synaptic vesicles. J Biomed Sci 10:774-781. CrossRef Medline

Christensen H, Fykse EM, Fonnum F (1991) Inhibition of gammaaminobutyrate and glycine uptake into synaptic vesicles. Eur J Pharmacol 207:73-79. CrossRef Medline

Crippa D, Schenk U, Francolini M, Rosa P, Verderio C, Zonta M, Pozzan T, Matteoli M, Carmignoto G (2006) Synaptobrevin2-expressing vesicles in rat astrocytes: insights into molecular characterization, dynamics and exocytosis. J Physiol 570:567-582. CrossRef Medline

Edelmann L, Hanson PI, Chapman ER, Jahn R (1995) Synaptobrevin binding to synaptophysin: a potential mechanism for controlling the exocytotic fusion machine. EMBO J 14:224-231. Medline

Edwards RH (2007) The neurotransmitter cycle and quantal size. Neuron 55:835-858. CrossRef Medline

El Mestikawy S, Wallén-Mackenzie A, Fortin GM, Descarries L, Trudeau LE (2011) From glutamate co-release to vesicular synergy: vesicular glutamate transporters. Nat Rev Neurosci 12:204-216. CrossRef Medline

Fairman WA, Vandenberg RJ, Arriza JL, Kavanaugh MP, Amara SG (1995) An excitatory amino-acid transporter with properties of a ligand-gated chloride channel. Nature 375:599-603. CrossRef Medline

Fossat P, Turpin FR, Sacchi S, Dulong J, Shi T, Rivet JM, Sweedler JV, Pollegioni L, Millan MJ, Oliet SH, Mothet JP (2012) Glial D-serine gates NMDA receptors at excitatory synapses in prefrontal cortex. Cereb Cortex 22:595-606. CrossRef Medline

Halassa MM, Haydon PG (2010) Integrated brain circuits: astrocytic networks modulate neuronal activity and behavior. Annu Rev Physiol 72: 335-355. CrossRef Medline

Hamilton NB, Attwell D (2010) Do astrocytes really exocytose neurotransmitters? Nat Rev Neurosci 11:227-238. CrossRef Medline

Harris KM, Sultan P (1995) Variation in the number, location and size of synaptic vesicles provides an anatomical basis for the nonuniform probability of release at hippocampal CA1 synapses. Neuropharmacology 34 : 1387-1395. CrossRef Medline

Hashimoto A, Nishikawa T, Oka T, Takahashi K, Hayashi T (1992) Determination of free amino acid enantiomers in rat brain and serum by high-performance liquid chromatography after derivatization with $\mathrm{N}$-tert-butyloxycarbonyl-L-cysteine and o-phthaldialdehyde. J Chromatogr 582:41-48. CrossRef Medline

Hell JW, Maycox PR, Jahn R (1990) Energy dependence and functional reconstitution of the gamma-aminobutyric acid carrier from synaptic vesicles. J Biol Chem 265:2111-2117. Medline

Henneberger C, Papouin T, Oliet SH, Rusakov DA (2010) Long-term potentiation depends on release of D-serine from astrocytes. Nature 463: 232-236. CrossRef Medline

Inoue R, Hashimoto K, Harai T, Mori H (2008) NMDA- and $\beta$-amyloid142 -induced neurotoxicity is attenuated in serine racemase knock-out mice. J Neurosci 28:14486-14491. CrossRef Medline

Jin H, Wu H, Osterhaus G, Wei J, Davis K, Sha D, Floor E, Hsu CC, Kopke RD, Wu JY (2003) Demonstration of functional coupling between gamma -aminobutyric acid (GABA) synthesis and vesicular GABA transport into synaptic vesicles. Proc Natl Acad Sci U S A 100:4293-4298. CrossRef Medline

Jourdain P, Bergersen LH, Bhaukaurally K, Bezzi P, Santello M, Domercq M, Matute C, Tonello F, Gundersen V, Volterra A (2007) Glutamate exocytosis from astrocytes controls synaptic strength. Nat Neurosci 10:331-339. CrossRef Medline

Juge N, Muroyama A, Hiasa M, Omote H, Moriyama Y (2009) Vesicular inhibitory amino acid transporter is a $\mathrm{Cl}^{-}$/gamma-aminobutyrate cotransporter. J Biol Chem 284:35073-35078. CrossRef Medline

Juge N, Gray JA, Omote H, Miyaji T, Inoue T, Hara C, Uneyama H, Edwards RH, Nicoll RA, Moriyama Y (2010) Metabolic control of vesicular glutamate transport and release. Neuron 68:99-112. CrossRef Medline

Kartvelishvily E, Shleper M, Balan L, Dumin E, Wolosker H (2006) Neuronderived D-serine release provides a novel means to activate $N$-methyl-Daspartate receptors. J Biol Chem 281:14151-14162. CrossRef Medline

Lapainis T, Rubakhin SS, Sweedler JV (2009) Capillary electrophoresis with electrospray ionization mass spectrometric detection for single-cell metabolomics. Anal Chem 81:5858-5864. CrossRef Medline

Martineau M, Baux G, Mothet JP (2006) D-serine signalling in the brain: friend and foe. Trends Neurosci 29:481-491. CrossRef Medline

Martineau M, Galli T, Baux G, Mothet JP (2008) Confocal imaging and tracking of the exocytotic routes for D-serine-mediated gliotransmission. Glia 56:1271-1284. CrossRef Medline

Maycox PR, Deckwerth T, Hell JW, Jahn R (1988) Glutamate uptake by brain synaptic vesicles. Energy dependence of transport and functional reconstitution in proteoliposomes. J Biol Chem 263:15423-15428. Medline

Miya K, Inoue R, Takata Y, Abe M, Natsume R, Sakimura K, Hongou K, Miyawaki T, Mori H (2008) Serine racemase is predominantly localized in neurons in mouse brain. J Comp Neurol 510:641-654. CrossRef Medline

Montana V, Ni Y, Sunjara V, Hua X, Parpura V (2004) Vesicular glutamate transporter-dependent glutamate release from astrocytes. J Neurosci 24: 2633-2642. CrossRef Medline

Mothet JP, Parent AT, Wolosker H, Brady RO Jr, Linden DJ, Ferris CD, Rogawski MA, Snyder SH (2000) D-serine is an endogenous ligand for the glycine site of the $\mathrm{N}$-methyl-D-aspartate receptor. Proc Natl Acad Sci U S A 97:4926-4931. CrossRef Medline

Mothet JP, Pollegioni L, Ouanounou G, Martineau M, Fossier P, Baux G (2005) Glutamate receptor activation triggers a calcium-dependent and SNARE protein-dependent release of the gliotransmitter D-serine. Proc Natl Acad Sci U S A 102:5606-5611. CrossRef Medline

Mustafa AK, van Rossum DB, Patterson RL, Maag D, Ehmsen JT, Gazi SK, Chakraborty A, Barrow RK, Amzel LM, Snyder SH (2009) Glutamatergic regulation of serine racemase via reversal of PIP2 inhibition. Proc Natl Acad Sci U S A 106:2921-2926. CrossRef Medline

Mustafa AK, Ahmad AS, Zeynalov E, Gazi SK, Sikka G, Ehmsen JT, Barrow RK, Coyle JT, Snyder SH, Doré S (2010) Serine racemase deletion protects against cerebral ischemia and excitotoxicity. J Neurosci 30:1413-1416. CrossRef Medline

Naito S, Ueda T (1985) Characterization of glutamate uptake into synaptic vesicles. J Neurochem 44:99-109. CrossRef Medline

Nemes P, Knolhoff AM, Rubakhin SS, Sweedler JV (2011) Metabolic differentiation of neuronal phenotypes by single-cell capillary electrophoresiselectrospray ionization-mass spectrometry. Anal Chem 83:6810-6817. CrossRef Medline

Panatier A, Theodosis DT, Mothet JP, Touquet B, Pollegioni L, Poulain DA, Oliet SH (2006) Glia-derived D-serine controls NMDA receptor activity and synaptic memory. Cell 125:775-784. CrossRef Medline

Puyal J, Martineau M, Mothet JP, Nicolas MT, Raymond J (2006) Changes in D-serine levels and localization during postnatal development of the rat vestibular nuclei. J Comp Neurol 497:610-621. CrossRef Medline

Rosenberg D, Kartvelishvily E, Shleper M, Klinker CM, Bowser MT, Wolosker H (2010) Neuronal release of D-serine: a physiological pathway controlling extracellular D-serine concentration. FASEB J 24:2951-2961. CrossRef Medline

Ryan RM, Mindell JA (2007) The uncoupled chloride conductance of a bacterial glutamate transporter homolog. Nat Struct Mol Biol 14:365-371. CrossRef Medline

Scanlan C, Shi T, Hatcher NG, Rubakhin SS, Sweedler JV (2010) Synthesis, accumulation, and release of D-aspartate in the Aplysia californica CNS. J Neurochem 115:1234-1244. CrossRef Medline

Schell MJ, Molliver ME, Snyder SH (1995) D-serine, an endogenous synaptic modulator: localization to astrocytes and glutamate-stimulated release. Proc Natl Acad Sci U S A 92:3948-3952. CrossRef Medline

Schenck S, Wojcik SM, Brose N, Takamori S (2009) A chloride conductance in VGLUT1 underlies maximal glutamate loading into synaptic vesicles. Nat Neurosci 12:156-162. CrossRef Medline

Strísovský K, Jirásková J, Mikulová A, Rulísek L, Konvalinka J (2005) Dual substrate and reaction specificity in mouse serine racemase: identification of high-affinity dicarboxylate substrate and inhibitors and analysis of the beta-eliminase activity. Biochemistry 44:13091-13100. CrossRef Medline Takamori S, Holt M, Stenius K, Lemke EA, Grønborg M, Riedel D, Urlaub H, Schenck S, Brügger B, Ringler P, Müller SA, Rammner B, Gräter F, Hub JS, De Groot BL, Mieskes G, Moriyama Y, Klingauf J, Grubmüller H, Heuser J, Wieland F, Jahn R (2006) Molecular anatomy of a trafficking organelle. Cell 127:831-846. CrossRef Medline

Volterra A, Meldolesi J (2005) Astrocytes, from brain glue to communication elements: the revolution continues. Nat Rev Neurosci 6:626-640. CrossRef Medline

Williams SM, Diaz CM, Macnab LT, Sullivan RK, Pow DV (2006) Immunocytochemical analysis of D-serine distribution in the mammalian brain 
reveals novel anatomical compartmentalizations in glia and neurons. Glia 53:401-411. CrossRef Medline 